\title{
Mediating social media use: Connecting parents' mediation strategies and social media literacy
}

\author{
Rowan Daneels ${ }^{1,2}$ \& Hadewijch Vanwynsberghe ${ }^{3}$ \\ ${ }^{1}$ Research group Media \& ICT in Organisations \& Society (MIOS), Faculty of Social Sciences, University of Antwerp, Antwerp, \\ Belgium \\ ${ }^{2}$ Institute for Media Studies (IMS), Faculty of Social Sciences, KU Leuven, Leuven, Belgium \\ ${ }^{3}$ Mediawijs - Flemish Knowledge Center for Media Literacy, Brussels, Belgium
}

\begin{abstract}
Increasingly complex and multipurpose social media platforms require digital competences from parents and adolescents alike. While adolescents grow up with social media, parents have more difficulties with them, leading to uncertainties regarding their adolescents' social media mediation. This study contributes to parental mediation research by (1) investigating whether mediation strategies defined by previous research are also relevant for social media use, and (2) exploring whether parents' social media literacy is connected to the choice for a certain mediation strategy, as previous research already identified other impact factors such as children's age or family composition. Using a qualitative research design, we interviewed 14 parents and 13 adolescents from 10 families in Belgium. Results indicate that, consistent with previous research, parents in this study mostly use active mediation focusing on risks and safety on social media. However, some parents monitor their children through social media accounts specifically set up for monitoring, or specialized mobile apps. Furthermore, parents with high (mostly critical) social media literacy choose active mediation over restrictive or technical strategies, recognizing opportunities of social media and letting adolescents explore on their own.
\end{abstract}

Keywords: Parental mediation; media literacy; social media; parents; adolescents

\section{Introduction}

The step from childhood towards adolescence goes hand in hand with several changes in the lives of adolescents. Young people become more autonomous and independent from their parents, spending more time with their friends and attaching more importance to them (Maccoby, 2007). It is also a period where adolescents are searching for their own identity and place in society (Kroger, 2007). Regarding this, digital and social media allow for more opportunities towards adolescents' freedom, identity formation and social relationship maintaining (boyd \& Ellison, 2008). Recent numbers showed that in 2016 for the case of Flanders (i.e., the Dutch-speaking part of Belgium), almost 4 out of 5 people (79\%) use at least one social media platform on a monthly basis (Imec, 2017). For adolescents, this number rises to 93\%, with 58\% indicating they use four or more social media profiles at least once a month (Imec, 2017). Hence, social media act as a central part of adolescents' lives.

Parents, however, did not grow up with social media the same way adolescents do. They often cannot keep up with continuously evolving digital changes, and frequently experience difficulties using social media platforms (Zaman, Nouwen, Vanattenhoven, de Ferrerre, \& Van Looy, 2016). Because of this, more uncertainties arise among parents about their own capabilities of using social media, all the while struggling to find the best way to 
mediate their children's social media use. For example, parents tend to fall back on limiting media behavior by using rules and monitoring media activities, while literature suggests these strategies are not always the best ones to avoid risks using for instance the internet (Livingstone \& Helsper, 2008).

Because of adolescents' frequent use of social media (Imec, 2017) and parents' uncertainties regarding social media parental mediation (Zaman et al., 2016), a study that delivers an in-depth understanding of (1) how parents engage in parental mediation of their adolescents' social media use and (2) how parents' social media literacy relates to the decision for a certain mediation strategy is needed, benefitting parents, adolescents, and parent-child relationships. To achieve this, we first reviewed previous research on both parental mediation within different media forms and social media literacy. We then conducted in-depth interviews with 27 participants: 13 adolescents between twelve and eighteen years old and 14 parents of 10 families. By interviewing adolescents and parents within the same families, this study distinguished itself from other studies as academic research often focuses on media experiences of children, adolescents or parents separately (Zaman et al., 2016). The focus on parental mediation of social media specifically and the exploration of the role of parents' social media literacy in the decision for a certain mediation strategy is also a new track in parental mediation research (Livingstone et al., 2017). This way, we will end up with a detailed image of social media parental mediation, social media literacy, and the relationship between both concepts.

\section{Digital and Social Media}

With innovations in communication technologies leading to more complex, mobile and multipurpose devices, these digital media can be defined as "mobile phones, laptops with Internet connection, and other devices that deliver entertainment such as television programming, films, games, and music (Clark, 2011, p. 324)". As a part of digital media, social media can be defined based on three specific characteristics: (1) communication through social media is deinstitutionalized, as users choose their own communication channels, (2) the receiver also becomes a sender with the rise of user-generated content, and (3) communication through social media is interactive and runs through networks (Bechmann \& Lomborg, 2013). Social network sites, as just one type of social media, have three specific aspects according to boyd \& Ellison (2008). Firstly, people can construct a public or semi-public profile with descriptive information about the user such as age, location and interests. Secondly, social network sites set up a list of other users with whom they share a relationship, frequently labeled as 'Friends' or 'Followers'. Thirdly, these connection lists are visible and are used to connect with other users.

\section{Parental Mediation}

As children start to use more digital media devices at an increasingly younger age (Zaman et al., 2016), they should be protected in this new environment by their parents, causing new parenting issues (Wartella, Rideout, Lauricella, \& Connell, 2013). Although parents often have no idea how to guide their children in their media use, they try to mediate their children's media behavior through various strategies (Warren, 2001). Previous research distinguished three overall parental mediation types, originating from the field of television studies: (1) restrictive mediation (i.e. parents enforcing rules on time and content to limit and control children's media use), (2) active mediation (i.e. parents having instructive or evaluative conversations with their children in order to explain or discuss children's use of digital media), and (3) co-use (i.e. parents sharing media activities with their children, driven by a common interest) (Gentile, Nathanson, Rasmussen, Reimer, \& Walsh, 2012; Nikken \& Jansz, 2006; Warren, 2001).

However, debate within the academic field exists on whether such 'general mediation strategies' are applicable to every type of media (Nikken \& Jansz, 2014). For instance, Symons, Ponnet, Emmery, Walrave, and Heirman (2017) performed a factorial validation study on parental mediation strategies regarding adolescents' internet use. They identified six distinct parental mediation strategies, which coincide with previous research (Livingstone, Haddon, Görzig, \& Olafsson, 2011; Livingstone \& Helsper, 2008): interaction restrictions (i.e. rules related to internet activities and behavior), monitoring (i.e. ad-hoc checking of adolescents' behavior), access restrictions (i.e. rules related to length and place of internet access), supervision and co-use (i.e. practices related to checking up and sharing internet activities), technical mediation (i.e. using software to limit or block access to certain websites); and interpretative mediation (i.e. discussing internet content with adolescents). Furthermore, Livingstone and colleagues (2017) suggested two different clusters of mediation strategies regarding internet 
use: enabling mediation, which responds to children's need for agency and results in more online opportunities but also more risks, and restrictive mediation, which is associated with fewer risks but also with fewer opportunities. Finally, Nikken and Jansz (2006) found evidence suggesting the same three mediation strategies related to watching television (i.e., restrictive mediation, active mediation, and co-use) can also be applied to playing digital games. The question remains whether the aforementioned mediation strategies also apply to social and digital media, having their own unique characteristics (boyd \& Ellison, 2008).

Dealing with digital media use, Zaman and colleagues (2016) studied three to nine year old children and distinguished several parental mediation strategies: restrictive mediation, active mediation, co-use, participatory learning, and distant mediation. While restrictive mediation, active mediation, and co-use strategies originate from previous studies (Gentile et al., 2012; Nikken \& Jansz, 2006; Warren, 2001), participatory learning and distant mediation are combinations of previously separate strategies. The first one combines both active mediation and co-use, and implies that parents invest in digital knowledge and skills. The second one consists of deference, referring to parents' conscious decision to give their children responsibility and autonomy in their digital media use, and supervision, where parents allow independent digital media use but keep a close eye on children's activities. Although the study by Zaman and colleagues (2016) is the only study mentioned here on young children instead of adolescents (which is the target group for this study), it is relevant because it includes the opinions of both children and parents, and it studies digital media, of which social media is a part of.

We assumed that some of the strategies from previous research (Livingstone et al., 2017; Symons et al., 2017; Zaman et al., 2016) could also be used for adolescents' social media use. For instance, as communication through social media is deinstitutionalized and interactive (Bechmann \& Lomborg, 2013), distant mediation and especially supervision would be a good fit to mediate social media use because of the agency and freedom adolescents experience while using social media. Active mediation could also be an important strategy, as parents discuss and evaluate for example the content their children share on or create with social media.

\section{Demographics, Context and Type of Media Impacting Parental Mediation Choices}

Choosing the best mediation strategy is not an easy job for parents. Besides often having no idea how to guide their children the best possible way, several factors also impact this choice. Sociodemographic factors for instance can impact that choice (Livingstone \& Helsper, 2008). Age of the child is a very important factor, with young children tending to be more on the receiving end of restrictive mediation than older ones (Nikken \& Jansz, 2014; Symons et al., 2017). Gender of the child sometimes has an effect on the choice of mediation, for instance with girls often being more restricted in their media use than boys (Livingstone et al., 2017). Parents' general media use and attitudes towards the medium also has an influence on mediation choice. For instance with gaming, parents who are raised with playing games and still play generally have a more positive attitude towards games and are more willing to adopt an active mediation strategy compared to parents who do not play at all (Nikken \& Jansz, 2006).

Besides demographic factors, context also plays a role in determining a mediation strategy. Zaman and colleagues (2016) suggested several contextual factors, split up into external and internal factors. External factors included for instance the weather and seasons, family composition, family schedule, and the infrastructure of the house. Internal factors included the attitudes of parents towards digital media regarding health, for instance focusing on a balanced life for their children with regular physical outdoor activities.

Finally, differences in mediation strategies can also be explained by the type of media and its characteristics. For example, Livingstone \& Helsper (2008) compared the internet with watching television and stated that the internet needs different mediation strategies because (1) using the internet is a less shared activity than watching television, (2) internet use is harder to monitor, and (3) the internet is a more interactive and therefore also more risky medium, for instance with the possibility to insert personal data on the internet.

With the unique characteristics of social media and the different elements influencing the choice for a specific mediation strategy, remarkably little research has been done to connect this choice with the social media literacy of parents (Livingstone et al., 2017). The relevance of investigating this connection lies in the fact that (1) digital and social media innovations require digital competences from parents to accompany their children on these 
platforms, and (2) having technical media knowledge and capabilities matters more in mediating children's internet and social media use than for instance watching television, because of its interactivity (Livingstone et al., 2017). Doing so, we first defined media literacy and what it entails in the specific case of social media use.

\section{Social Media Literacy and its Impact on Choosing Parental Mediation Strategies}

The concept of media literacy has had a long history with a number of different definitions and complex interpretations (Livingstone, 2004; Livingstone, van Couvering, \& Thumin, 2008). In our current study, we employed the definition of social media literacy being "the technical and cognitive competencies users need to use social media in an effective and efficient way for social interaction and communication on the web" (Vanwynsberghe, Boudry, \& Verdegem, 2015, p. 85). In this definition, technical competencies refer to knowledge and skills to create, navigate, organize, produce, and share social media content. Cognitive competencies, on the other hand, include the analysis and evaluation of social media content (Livingstone, 2004), and refer to critically understanding social media content in its context, relevance, and trustworthiness (Vanwynsberghe, 2014).

Parental mediation theory states that parents employ several strategies attempting to mediate negative effects of media in their adolescents' lives, while also assuming that media can educate adolescents in social and informative manners (Clark, 2011; Helsper, 2012). The notion of social media literacy connects to this interpretation of parental mediation, as it refers to the ability towards maximizing opportunities on social media platforms while also minimizing potential risks by knowing how to operate and evaluate media content (Vanwynsberghe et al., 2015). Both imply enhancing advantages and fend off disadvantages while using social media.

Few studies have looked into the relationship between social media literacy with its specific competencies and the choice for a mediation strategy. Recent work by Livingstone and colleagues (2017) studied what role digital skills of both parents and children have in choosing a mediation strategy. They showed that the strategy of enabling mediation (i.e., children's need for agency, resulting in more opportunities and more risks) is being used more by parents who are more digitally skilled and for children who have more digital skills, and vice versa for restrictive mediation (i.e., mediation associated with less risks but also with less opportunities). Despite this, the impact of parents' digital skills on mediation choice proved to be rather slim. The current study further explored this connection, as the study by Livingstone and colleagues (2017) focuses only on digital skills or technical competencies, neglecting cognitive-critical competencies which are necessary to fully use and understand social media content (Vanwynsberghe et al., 2015).

\section{Present Study}

Previous research within the field of parental mediation has determined different strategies parents use to mediate children and adolescents television (Warren, 2001), internet (Livingstone et al., 2017; Symons et al., 2017), digital game (Nikken \& Jansz, 2006) and digital media use (Zaman et al., 2016). As a first objective, the current study investigated how parents engage in parental mediation regarding their adolescents' social media use, and whether they corresponded with mediation strategies used with other types of media. The corresponding research question can be formulated as:

\section{RQ1: How do parents engage in parental mediation with regard to adolescents' social media use?}

Likewise, previous research posited several factors influencing the decision of which mediation strategies to use, including gender (Livingstone et al., 2017) and age of the children (Nikken \& Jansz, 2014; Symons et al., 2017), general media use and attitudes towards media (Nikken \& Jansz, 2006), and contextual factors (Zaman et al., 2016). As a second goal, the present study explored how parents' social media literacy (i.e., the technical and cognitive competencies needed to efficiently use social media; see Vanwynsberghe et al., 2015) relates to the decision for a certain mediation strategy. We therefore wonder:

RQ2: How does parents' social media literacy, existing of both technical and cognitive competencies, relate to the decision for a certain mediation strategy? 
This question is needed as both parental mediation and social media literacy involve the ability towards maximizing opportunities of media behavior while also minimizing potential risks (Clark, 2011; Vanwynsberghe et al., 2015).

\section{Methods}

\section{Procedure}

Using a qualitative research design, this study is situated within the broader Mediawijs 'Youth Research' on adolescents' digital media use within the family context. More specifically, we performed in-depth interviews of approximately two hours each, with an open questioning system instead of closed questions to gather detailed and rich data (Mortelmans, 2011) on parental mediation strategies and social media literacy. The interviews took place between February and April 2016 in Flanders, the Dutch-speaking region of Belgium. We conducted the interviews at the participants' homes to include the family context of social media use. Both parents and the underage adolescents signed informed consents, interviews were registered with a tape recorder, typed verbatim and transcripts were anonymized.

Prior to the interviews, the participants were informed of the goals of the study, the participants' rights, and confidentiality of the data. First off, both parents and adolescents were interviewed together as an ice-breaker. Using a daily schedule, the participants talked about access and use of social media within the family. Additional questions in this phase were for instance 'I see you do activity $X$ quite often. On which device is this usually?' or 'Is this pattern on the schedule also the same during the weekend, or is this different?'. After the ice-breaker conversation, respondents were separated for their own interview.

Parents talked about their social media experiences using a card system consisting of four different rounds, with the first three including pictograms of (1) social media profiles, (2) online activities (e.g., sharing, liking, commenting), and (3) online content (e.g., photos, videos), to deliver descriptive data on general social media use. For instance, parents were encouraged to talk about which social media they use, why they use some profiles more often than other, etc. In the fourth round, parents received cards with certain social media related concepts and news headlines on them. Examples of concepts were 'addiction', 'privacy', and 'antisocial', while examples of headlines were '50\% of parents keep an eye on things online' and 'Adolescents: Facebook needs to intervene faster regarding offensive content'. The underlying idea was to stimulate parents to think about these concepts and headlines in association with their own or their children's social media use, giving their opinion on the items and reflecting on them regarding their own family situation.

Adolescents were asked about their general social media use in the same way as the parents, using the three rounds of pictograms. Additionally, they were asked about their opinions regarding several social media related issues by means of an evaluation tool using colored flags. In this phase, they received several scenarios on topics ranging from privacy and copyrights to grooming and sexting. For example, one scenario included the following situation: 'Jack and Kenny are bored during the break at school and decide to prank a classmate. They create a fake profile of a girl and begin to chat with Joey, another boy in their class.'. They were asked to evaluate each scenario with a specific color of flag (which ranged from black as 'totally not cool' to green as 'no problem at all'), discussing each scenario and evaluation afterwards.

\section{Sample}

We used theoretical sampling in this study because of its exploratory nature and focus on the selection of information rich participants. We questioned in total 13 adolescents and 14 parents, within 10 families (see Table 1). Participants were selected based on the sampling criteria of gender (adolescents: 9 girls, 4 boys; parents: 9 mothers, 5 fathers), age (adolescents between 12-18 years old; parents between 35-53 years old), and residence (living in urban and rural areas), creating a balanced sample. The families were contacted through a call on both the website and social media channels of Mediawijs, the Flemish Knowledge Center for Media Literacy. 


\section{Analysis}

Analysis of the collected data occurred through qualitative coding, using the NVivo 11 software package as a tool to organize and structure all information. Data analysis was performed using both inductive and deductive techniques: labels were categorized in broad themes set beforehand based on our research objectives, while data was also structured by searching for themes that emerged from the data itself (Spencer, Ritchie, Ormston, O'Connor, \& Barnard, 2014). For instance, with the theme of 'social media literacy', we inductively categorized parts of the interview belonging to either technical or cognitive-critical competencies, while also deductively labelling for instance all the reasons parents gave for their little technical knowledge on social media. We performed multiple rounds of identifying, organizing, and re-organizing themes until no new themes emerged from the data.

To assure quality of the coding process, the two researchers involved with interviewing also performed the data analysis. After the first coded interview, the researchers compared codes and made adjustments so that the process of code assignment was as similar as possible between the two researchers.

Table 1. Demographic Information Participants.

\begin{tabular}{|c|c|c|c|c|}
\hline & Parent 1 & Parent 2 & Adolescent 1 & Adolescent 2 \\
\hline Family 1 & Female, age 52 & & Male, age 17 & \\
\hline Family 2 & Female, age 39 & & Male, age 16 & Female, age 13 \\
\hline Family 3 & Male, age 39 & Female, age 35 & Female, age 12 & \\
\hline Family 4 & Male, age 39 & Female, age 38 & Female, age 12 & \\
\hline Family 5 & Female, age 44 & & Female, age 15 & \\
\hline Family 6 & Female, age 48 & & Female, age 14 & \\
\hline Family 7 & Male, age 49 & & Female, age 16 & \\
\hline Family 8 & Female, age 46 & Male, age 48 & Male, age 17 & Female, age 15 \\
\hline Family 9 & Female, age 47 & & Female, age 16 & Male, age 16 \\
\hline Family 10 & Male, age 53 & Female, age 42 & Female, age 16 & \\
\hline
\end{tabular}

\section{Results}

In the following paragraphs, results from our interviews will be used to address the two research questions, being (1) how parents engage in parental mediation of their adolescents' social media use and (2) how parents' social media literacy relates to the decision for a certain mediation strategy. To this extent, we will present insights from both parents and adolescents.

\section{Parental Mediation Strategies of Social Media Use}

Based on the interviews, we found several strategies used by parents to mediate their adolescents' social media use. Overall, we identified the strategies of active, restrictive, and distant mediation - the latter split up into deference and supervision - and discussed them in the following paragraphs.

Active mediation. All of the interviewed parents stated they often use active mediation strategies, specifically focusing on safety on social media platforms. They try to communicate openly with their children on the use of social media and other related issues such as online privacy. One parent said the following: 
Many of the interviewed parents believed in open communication as an essential part of social media education and mediation of adolescents. They often did this in function of safety and risks on the internet, warning them to look out for online dangers and what they post online in the hope of making their children more critical when using social media. Only in three out of ten families, parents talked about the opportunities of social media with adolescents. The ones that did, talked about social media being "informative on for instance local events" (F,52 on $M, 17)$, being useful to "keep in touch with friends" $(F, 39$ on $F, 13)$ or "prepare adolescents for a professional life where technological capabilities are often required" (M,39 on $F, 12)$.

Communication about social media, however, is not something random. Both parents and adolescents indicated talking about social media is often caused by some sort of event or incidence, for instance adolescents seeing inappropriate video clips on YouTube or not knowing how to deal with a friend being cyberbullied. Another example was, in response of a news report, talking about for instance sexting and sending explicit images via social media. Parents often used news reports to ask their children questions such as "have you ever dealt with this?" or to remark they ought to be careful with what they post online. Besides this, parents also discussed social media content with their children because they otherwise have no idea what their children do on social media. One mother formulated this concern as following: "I often wonder what they are doing on social media, so I try to talk to them about their activities" $(F, 42)$.

Restrictive mediation. In our current study, we see that the choice of using restrictive mediation strategies is mostly applied by parents with younger adolescents, aged 12 to 14 years. These rules and limitations specifically focused on time (e.g., not spending too much time on social media) and location (e.g., no smartphones and laptops allowed in the bedroom). Reasons for parents to set rules were because of the adolescents would else "use their smartphone after bedtime" $(F, 48$ on $F, 14)$ or "neglect chores or playing outside" $(M, 39$ on $F, 12)$.

"Yeah, we do not allow them to use their smartphones or other devices in their own rooms." (F,35 on F,12)

Distant mediation: Deference. Although some parents have rules involving the use of social media, they are less strict for adolescents than for pre-adolescent children. Around half of the interviewed parents - mostly of older adolescents - indicated they realize not having full control over their children's social media use, hence not enforcing rules or at least not as strict as they would like to. Parents see how their rules are often bended or bypassed by the inventiveness of adolescents, for instance "using mobile internet on their smartphones when parents shut down the Wi-Fi" (M,53 on F,16).

In cases like this, parents kept their distance and trusted their children in using social media. This is not just because of the inefficiency of rules among older adolescents. Trusting adolescents with more freedom and responsibility is, according to the parents from eight out of ten families, a part of growing up:

"You need to have a bit of trust and give them some space to experiment. It's the same as in other parts of education: giving them responsibility is a part of becoming an adult." (F,39 on $\mathrm{M}, 16$ and $\mathrm{F}, 13)$

Besides the fact that giving trust is a part of the path towards adulthood, parents also reported they trust their children to be "old enough" ( $F, 52$ on $M, 17)$ and "smart enough" $(F, 46$ on $M, 17$ and $F, 15)$ to be cautious with certain content and personal data for instance. This relates to the notion of 'third-person effect', where parents view their own child as more mature than most others, often underestimating the influence of social media on their children compared to the influence on other people's children. For instance, one mother indicated that:

"I try to give them some space and trust them. I do believe they use it [social media] in the right way. [...] I believe they have not that many issues with using social media compared to other classmates." (F,44 on $\mathrm{F}, 15)$

Distant mediation: Supervision. While a lot of parents gave their adolescents some trust when using social media, they also tended to check up on them. However, the way supervision is being staged has evolved along with digital innovations. Supervision used to be - and sometimes still is, according to a small number of parents we interviewed - performed by checking online activities through being in the neighborhood or checking their browser history, through profiles of siblings or even grandparents. 
"We said to her she could only use Facebook when we are also downstairs, for instance if we are cooking and we can see what she is doing at the same time." $(\mathrm{M}, 39$ on $\mathrm{F}, 12)$

The interviewed parents indicated they have a harder time monitoring media use in the case of social media, for instance because of the complexity of digital media devices. Another reason was that adolescents tend to be less active than they used to be on generally known platforms such as Facebook, and post more online through platforms their parents do not use or not even know off, such as Instagram or Snapchat. In our study, almost all of the adolescents had an account on Facebook and on lesser known social media platforms such as Snapchat and Instagram. One adolescent mentioned:

"I only use Instagram and Snapchat to send pictures to my friends. [...] Frankly, if you could use Messenger without a Facebook-account, I probably would have already deleted my Facebook profile." $(\mathrm{F}, 15)$

The interviewed parents in our study indicated they also monitor their adolescents' social media use by (1) making a social media account dedicated for this one purpose, (2) using a monitoring mobile app, or (3) communicating with their children through social media (e.g., photo comments, WhatsApp). One dad, for instance, stated that he "mostly watches by using a mobile app, the 'Mobile Fence'-app. Everything happening on her smartphone, I see as well." (M,49 on F,16). He could see the frequency of use, which content she saw, block inappropriate content, locate the smartphone, etc. This rather extreme way of supervision was invoked when the daughter showed excessive (in the eyes of her parents) smartphone use. However, they did "not go through her text messages for instance, that is too personal." Interesting to notice is that this specific manifestation of supervision, i.e. monitoring adolescents by using social media accounts or other mobile applications, was not mentioned before in previous research on parental mediation of adolescents.

\section{Social Media Literacy of Parents: How Does it Relate to Parental Mediation?}

In this section of the results, we first looked at how parents rate their social media literacy before connecting these statements with their parental mediation strategies.

As we conceptualized social media literacy as both technical and cognitive-critical competencies, social media literacy of the questioned parents can be summarized as seriously lacking technical skills but having a critical attitude towards social media to compensate for this. The technical competences of most parents were low due to little use of social media platforms. Eleven out of fourteen parents indicated they have a Facebook profile, with seven using it daily. However, this daily use was often limited to using Facebook passively: they use it to follow other people instead of posting content themselves. Besides this, they would "most likely give a 'thumbs up' than place a comment or share something" $(F, 35)$. Other social media such as Instagram, Snapchat or YouTube are either less used, only to monitor their adolescents, or not at all, implying parents have little understanding of what these social media can do and what content is being spread on those platforms. This kind of passive, Facebook only type of social media use is caused by a lack of time or interest, and by uncertainties about their abilities. The parents of family 4 described it as:

"Actually, we don't use that much social media. Because we are both busy, we don't have the time for it." $(\mathrm{F}, 35$ and $\mathrm{M}, 39)$

Because of this little use, issues with privacy or profile settings, issues with making or removing a social media account or finding certain content on social media often occurred. One mother indicated having difficulties with some Facebook functions:

"I tried to access my privacy settings of Messenger through my tablet, to ensure that, if my daughter uses my tablet, see would not receive my messages. But I couldn't find out how to do this. [...] Another issue was to log out of Facebook through my tablet. I couldn't find this either. Or sharing something with only one person." $(F, 48)$.

Compensating for lacking technical skills, almost all parents were critically occupied with potential risks on social media. They did not hide from social media and the importance it has in their children's lives, but consciously 
and critically dealt with it. For instance, one parent contemplated about the role of social media companies such as Facebook as a commercial enterprise:

"Handing companies such as Facebook control over which content needs to be removed [if it's inappropriate] and trusting them to have the best interest with your privacy? Watch out! Facebook is still a commercial company wanting to make a profit." $(\mathrm{F}, 48$ on $\mathrm{F}, 14)$

Parents also indicated trying to pass on this critical attitude towards social media use to their children. They organized this for instance by watching documentaries on media literate topics together and discussing them during or afterwards. This is a first clear indication of the link between social media literacy of parents and the choice for mediation strategy, as this 'discussion' refers to parents with high critical attitudes choosing to use active mediation strategies over other mediation strategies.

"I record such documentaries on for instance cyberbullying or sexting, and then we watch them together. This then mostly leads to a discussion or talk on the subject." (F,39 on $\mathrm{M}, 16$ and $\mathrm{F}, 13)$

However, this passing down remains scarce: only three out of fourteen parents reported doing this, and only if there is a lead to talk about it, such as an incidence in the news or in their direct environment.

The self-perceived low amount of social media literacy, especially in terms of lacking technical skills, made parents question their contributions towards the social media education of their adolescents.

"These youngsters have no troubles with all those innovations. We as parents have to go to them for explanations, so what can we contribute?" $(\mathrm{M}, 53$ on $\mathrm{F}, 16)$

When we asked the interviewed adolescents about this notion, they debunked the idea immediately. Parents do contribute to their digital media education, focusing specifically on the critical attitude part of media literacy. They indicated that, similar to what the parents said, they are being warned about posting explicit or inappropriate content such as bikini photos or the danger of chatting online with strangers. One girl said that "her mother told her photos on social media can be hacked by people with bad intentions" (F,13 on F,39), while another girl said "to be aware of accepting friend requests by strangers" $(F, 12$ on $F, 35)$ because of her parents. The majority of interviewed adolescents did mention they learn little to nothing from their parents when it comes to technical skills. Their knowledge mostly came from trial-and-error or from friends, as one adolescent formulated: "I have learned how to set up a Facebook account on my own" $(\mathrm{M}, 17)$.

Parents tried to pass on a critical attitude towards social media use to their children, recognizing both the potential dangers and advantages of social media. By using active mediation, they let their adolescents explore social media on their own terms. One mother explained it as following: "I think it's really important to trust them in using social media and other online applications. It's the only way to let them make mistakes and hopefully learn from them" $(F, 39)$. This is a clear connection between the social media literacy of parents and choosing a mediation strategy. However, this was not the only connection coming from the results. For instance, one parent showed more technical skills with computers and mobile devices than the other parents, having a relatively high amount of social media literacy. In this case, he applied supervision and restrictive mediation to his daughter's smartphone and social media use by monitoring her using a mobile app on his own device.

"Using the app, I can block for instance violent or drug-related content. [...] I can also immediately track her location if something happens." (M,49 on $\mathrm{F}, 16)$

\section{Discussion and Conclusion}

The first objective was to examine how parents engage in parental mediation of their adolescents' social media use, and whether this concurs with strategies identified in previous research. The interviewed parents mostly 
used the same parental mediation strategies to moderate their adolescents' social media use as mentioned in previous research on digital media and internet use of adolescents and children (Livingstone et al., 2011; Symons et al., 2017; Zaman et al., 2016). Active or interpretative mediation with regard to risks and safety on social media platforms is used most often. Next to this, restricting social media use is being used especially among parents of younger adolescents (between 12 and 14 years old), which is in line with previous studies (Nikken \& Jansz, 2014; Symons et al., 2017). Distant mediation, in the form of both trusting adolescents with their social media use and monitoring them - as delineated in the study by Zaman and colleagues (2016) - was also present in the arsenal of mediation strategies for adolescents' social media use. Supervision is an often chosen strategy because of the agency adolescents have while using social media, since communication through social media tends to be deinstitutionalized and interactive (Bechmann \& Lomborg, 2013). We also found a new manifestation of monitoring media use in our study, with parents using mobile applications and social media accounts only for monitoring purposes. This manifestation should be further studied in future research. Remarkably, the co-use strategy has not been mentioned at all by the interviewed parents. A possible explanation for this is that using social media through devices such as computers, smartphones or tablets is less a shared activity than for instance watching television (Clark, 2011; Livingstone et al., 2011). Another explanation is that co-use is a mediation strategy often used among younger children, for instance parents who sit together with their children who use a certain medium for the first time (Zaman et al., 2016).

Next to this, our second objective was to explore how social media literacy of parents related to the choice of a mediation strategy. While parents recorded low technical competencies, mostly due to a lack of time or interest, cognitive-critical competencies were showed more often by the interviewed parents: for instance, being aware of the commercial goals of social media companies such as Facebook. Connecting this to the parental choice of a mediation strategy, we found that parents having a critical attitude - passing on warnings to their children about potential risks or talking about safety on social media - led to parents choosing more active, enabling or interpretative mediation (Livingstone et al., 2017; Symons et al., 2017), giving adolescents the opportunity to discover the advantages and risks of social media on their own. This is in line with a recent study by Livingstone and colleagues (2017). However, one parent with higher technical competencies used more restrictive and monitoring mediation strategies. This could possibly be explained as parents with more (technical) knowledge also know how to use for instance monitoring applications.

\section{Limitations and Future Research}

There were some limitations to this study. Firstly, although it is interesting to show a connection between the social media literacy among parents and the choice for a certain mediation strategy in our sample, using qualitative research, we have no idea (1) how strong the impact of social media literacy of parents is on the choice of parental mediation strategy, (2) if the found connections can be generalized to a broader population of parents, and (3) which other factors such as age or specific characteristics of the children (Livingstone et al., 2011) might possibly influence this choice alongside social media literacy. Despite the recent study of Livingstone and colleagues (2017) suggesting that digital skills of parents - as one part of (social) media literacy - only has little added value in explaining the choice for a certain mediation strategy, future research should look into the full concept of (social) media literacy and its possible connection with parental mediation. Further, future research should also look to validate or refute the following potential distinction: parents with more technical competencies tend to choose restrictive and supervision mediation, while parents with more cognitive-critical competencies choose more active mediation strategies.

Based on our results, a number of recommendations can be made. For parents, an important recommendation lies in the importance of dialogue and involvement. We advise parents to be more invested in and involved with their children's activities on social media. Adolescents should therefore be assisted in their social media use, especially since this phase in their lives implies more risk-taking behavior and a search for their own identity (Kroger, 2007; Maccoby, 2007). Because of this, parents need help and support to deal with these issues. Next to this, one parent indicated tracking his daughter's social media activities to such an extent it might be considered as unwanted and invasive. This worrying result is relevant to frame within the emerging research field of children's rights related to digital media practices (Livingstone \& Third, 2017), with the increasing use of digital media leading to new risks for children (Third, 2016). This specific example of extreme monitoring can also be framed in a trade-off between the parents' responsibilities and adolescents' need for autonomy. 
The main contribution of this study is that it offers a unique insight into parents' and adolescents' uses and views on social media within the same family. This study also shows that previously uncovered mediation strategies apply to the specific case of social media use as well, although the replication is in a small sample. Finally, it is a first step in exploring whether (social) media literacy of parents is important to pinpoint which mediation strategy parents will use, which is a recent track in parental mediation research (Livingstone et al., 2017) that certainly needs further attention.

\section{References}

Bechmann, A., \& Lomborg, S. (2013). Mapping actor roles in social media: Different perspectives on value creation in theories of user participation. New Media \& Society, 15, 765-781.

https://doi.org/10.1177/1461444812462853

boyd, D. M., \& Ellison, N. B. (2008). Social network sites: Definition, history, and scholarship. Journal of ComputerMediated Communication 13, 210-230. https://doi.org/10.1111/j.1083-6101.2007.00393.x

Clark, L. (2011). Parental mediation theory for the digital age. Communication theory, 21, 323-343.

https://doi.org/10.1111/j.1468-2885.2011.01391.x

Gentile, D. A., Nathanson, A. I., Rasmussen, E. E., Reimer, R. A., \& Walsh, D. A. (2012). Do you see what I see? Parent and child reports of parental monitoring of media. Family Relations, 61, 470-487.

https://doi.org/10.1111/j.1741-3729.2012.00709.x

Helsper, E. J. (2012). A corresponding fields model of digital inclusion. Communication Theory, 22, 403-426. https://doi.org/10.1111/j.1468-2885.2012.01416.x

Imec (2017). Digimeter 2016. Retrieved from https://www.imec-int.com/digimeter

Kroger, J. (2007). Identity development: Adolescence through adulthood. Thousand Oaks, CA: Sage.

Livingstone, S., Ólafsson, K., Helsper, E., Lupiáñez-Villanueva, F., Veltri, G., \& Folkvord, F. (2017). Maximizing opportunities and minimizing risks for children online: The role of digital skills in emerging strategies of parental mediation. Journal of Communication, 2017, 1-24. https://doi.org/10.1111/jcom.12277

Livingstone, S., \& Third, A. (2017). Children and young people's rights in the digital age: An emerging agenda. New Media \& Society, 19, 657-670. https://doi.org/10.1177/1461444816686318

Livingstone, S., Haddon, L., Görzig, A., \& Ólafsson, K. (2011). Risk and safety on the internet. The perspective of European children. Full findings from the EU Kids Online survey of 9-16 year olds and their parents. London, UK: EU Kids Online. Retrieved from http://yil5.inet-

tr.org.tr/akgul/eukids/Risks\%2520and\%2520safety\%2520on\%2520the\%2520internet\%25281sero\%2529.pdf

Livingstone, S., van Couvering, E., \& Thumin, N. (2008). Converging traditions of research on media and information literacies: Disciplinary, critical, and methodological issues. In J. Coiro, M. Knobel, C. Lankshear, \& D. J. Leu (Eds.), Handbook of research on new literacies (pp. 103-132). New York, USA: Routledge.

Livingstone, S., \& Helsper, E. (2008). Parental mediation of children's internet use. Journal of Broadcasting \& Electronic Media, 52, 581-599. https://doi.org/10.1080/08838150802437396

Livingstone, S. (2004). What is media literacy? Intermedia, 32(3), 18-20. Retrieved from http://eprints.Ise.ac.uk/1027/1/What_is_media_literacy_(LSERO).pdf

Maccoby, E. E. (2007). Historical overview of socialization research and theory. In J. Grusec \& P. Hastings (Eds.), Handbook of socialization: Theory and research (pp. 13-41). New York City, USA: The Guilford Press.

Mortelmans, D. (2011). Handboek kwalitatieve onderzoeksmethoden [Handbook of qualitative research methods]. Leuven: Acco.

Nikken, P., \& Jansz, J. (2014). Developing scales to measure parental mediation of young children's internet use. Learning, Media and Technology, 39, 250-266. https://doi.org/10.1080/17439884.2013.782038 
Nikken, P., \& Jansz, J. (2006). Parental mediation of children's videogame playing: A comparison of the reports by parents and children. Learning, Media and Technology, 31, 181-202. https://doi.org/10.1080/17439880600756803

Spencer, L., Ritchie, J., Ormston, R., O'Connor, W., \& Barnard, M. (2014). Analysis: Principles and processes. In J. Ritchie, J. Lewis, C. McNaughton Nichols, \& R. Ormston (Eds.), Qualitative research practice, $2^{\text {nd }}$ ed. (pp. 269-293). London, UK: Sage.

Symons, K., Ponnet, K., Emery, K., Walrave, M., \& Heirman, W. (2017). A factorial validation of parental mediation strategies with regard to internet use. Psychologica Belgica, 57, 93-111.

https://doi.org/https://doi.org/10.5334/pb.372

Third, A. (2016). Researching the benefits and opportunities for children online. London: Global Kids Online. Retrieved from: http://blogs.Ise.ac.uk/gko/wp-content/uploads/2016/06/Guide-6-Global-opportunities-forchildren-Third.pdf

Vanwynsberghe, H., Boudry, E., \& Verdegem, P. (2015). De impact van ouderschapsstijlen op de ontwikkeling van sociale mediageletterdheid bij adolescenten [The impact of parenting styles on the development of social media literacy among adolescents]. Tijdschrift voor Communicatiewetenschap, 1(43), 84-100.

Vanwynsberghe, H. (2014). How users balance opportunity and risk: A conceptual exploration of social media literacy and measurement [Unpublished doctoral dissertation]. Ghent, Belgium: Ghent University.

Warren, R. (2001). In words and deeds: Parental involvement and mediation of children's television viewing. The Journal of Family Communication, 1, 211-231. https://doi.org/10.1207/S15327698JFC0104_01

Wartella, E., Rideout, V., Lauricella, A., \& Connell, S. (2013). Parenting in the age of digital technology. Report for the Center on Media and Human Development. Illinois, USA: Northwestern University. Retrieved from https://contemporaryfamilies.org/wp-content/uploads/2014/04/Wartella.pdf

Zaman, B., Nouwen, M., Vanattenhoven, J., de Ferrerre, E., \& Van Looy, J. (2016). A Qualitative inquiry into the contextualized parental mediation practices of young children's digital media use at home. Journal of Broadcasting \& Electronic Media, 60, 1-22. https://doi.org/10.1080/08838151.2015.1127240

\section{Correspondence to:}

Rowan Daneels

Faculty of Social Sciences

University of Antwerp

Sint-Jacobstraat 2

2000 Antwerp, Belgium

Email: rowan.daneels(at)uantwerpen.be

Editorial record: First submission received on April 28, 2017. Revision received on June 14, 2017, September 28, 2017, and October 23, 2017. Accepted for publication on October 30, 2017.

The article is part of the Special Issue "Young children's use of digital media and parental mediation" guest edited by Bieke Zaman and Charles Mifsud. The guest editors thank Natalia Kucirkova for supporting the editorial process for this paper in its initial peer review stages. 


\section{About Authors}

Rowan Daneels, MSc in Communication Studies at the University of Antwerp (2014) and Ghent University (2015), and former Teaching Assistant at the Institute for Media Studies, KU Leuven, is now a Teaching Assistant and PhD Researcher at the MIOS research group, University of Antwerp. His research interests include digital games, virtual reality, and media literacy; especially studying adolescents as a target group.

Hadewijch Vanwynsberghe, PhD in Communication Studies at Ghent University (2014) with a dissertation on the conceptualization and measurement of social media literacy, is the Research Coordinator at Mediawijs, the Flemish knowledge center for media literacy. Her research interests include media literacy and digital media, with a specific interest in valorizing research with different stakeholders. 